\title{
Enhance Your Team-Based Qualitative Research
}

\author{
Douglas H. Fernald, $M A^{1}$ \\ Christine W. Duclos, $P b D^{2}$ \\ 'Department of Family Medicine, University \\ of Colorado at Denver and Health Sciences \\ Center, Aurora, Colo \\ ${ }^{2} J S I$ Research and Training Institute, Denver, \\ Colo
}

Conflicts of interest: none reported

\section{CORRESPONDING AUTHOR}

Douglas Fernald, MA

PO Box 6508 F496

Aurora, Colorado, 80045-0508

doug.fernald@uchsc.edu

\begin{abstract}
PURPOSE Qualitative research projects often involve the collaborative efforts of a research team. Challenges inherent in teamwork include changes in membership and differences in analytical style, philosophy, training, experience, and skill. This article discusses teamwork issues and tools and techniques used to improve teambased qualitative research.
\end{abstract}

METHODS We drew on our experiences in working on numerous projects of varying, size, duration, and purpose. Through trials of different tools and techniques, expert consultation, and review of the literature, we learned to improve how we build teams, manage information, and disseminate results.

RESULTS Attention given to team members and team processes is as important as choosing appropriate analytical tools and techniques. Attentive team leadership, commitment to early and regular team meetings, and discussion of roles, responsibilities, and expectations all help build more effective teams and establish clear norms. As data are collected and analyzed, it is important to anticipate potential problems from differing skills and styles, and how information and files are managed. Discuss analytical preferences and biases and set clear guidelines and practices for how data will be analyzed and handled. As emerging ideas and findings disperse across team members, common tools (such as summary forms and data grids), coding conventions, intermediate goals or products, and regular documentation help capture essential ideas and insights.

CONCLUSIONS In a team setting, little should be left to chance. This article identifies ways to improve team-based qualitative research with more a considered and systematic approach. Qualitative researchers will benefit from further examination and discussion of effective, field-tested, team-based strategies.

Ann Fam Med 2005;3:360-364. DOI: 10.1370/afm.290.

\section{INTRODUCTION}

W hen conducting qualitative research-especially large, multiyear projects—-working in teams has some advantages. Projects benefit from the collective labor, thought, skill, and energy that team members bring. Teams also advance the academic goals of learning from others and transferring knowledge across disciplines and institutions. Teams can be especially good for gathering and analyzing large amounts of qualitative data. The challenge comes in sustaining the effort to the end of a project and into the next project. Some of the challenges come from the nature of qualitative inquiry: because understanding comes iteratively at all phases of the project, essential ideas, insights, and connections can come from different members of a team at different points in time. Keeping good records and processes become essential. Unfortunately, we often do not realize avoidable problems until we are in the midst of them.

Despite published accounts of team-based qualitative research, ${ }^{1-11}$ there are few concise, concrete, practical suggestions for how a team goes about improving the team and its work. Furthermore, investigators must be confident that processes and findings will stand up to peer scrutiny, ${ }_{1}^{12-15}$ 
which can be more difficult as data, analysis, and results are spread across team members, computers, departments, or institutions. Teams must find ways to manage and analyze large amounts of data, deal with subtle change that occurs with time, and reduce the competing demands and crises that may disrupt the effort. We do not propose a specific qualitative method; instead, we discuss issues we have encountered and synthesize the tools and techniques we used to improve our teambased qualitative research.

\section{METHODS}

We drew on a decade of experience working on team projects of varying size, duration, methodology, and purpose. Our work has spanned departments, institutions, disciplines, and cultures, including multimethod research in family medicine, evaluation of statewide health education and health promotion programs, and research and analysis in nutrition, patient safety, medical education, mental health, criminal justice, sexual health, health policy, and participatory research with tribal communities. In each of these undertakings, the collaborative efforts ranged from design and planning, to implementation and data collection, to analysis and reporting. Through trials and refinement of different tools and techniques, expert consultation, and review of the literature, we learned to improve how we build teams, manage information, and disseminate results. In this article, we illustrate some of our methods using a more etic approach (based on the researcher's concepts and research questions) to qualitative research; however, we feel that our lessons learned can be helpful for other approaches, including more naturalistic or emic approaches (deriving from the conceptual framework of those being studied).

\section{RESULTS}

\section{Issues In Teamwork}

\section{Teams: People and Processes}

Challenges inherent in teamwork include changes in membership, along with differences in analytical style, philosophy, training, experience, language, and skill. Teamwork suffers when the right people work on the wrong things at the wrong time, or when roles, expectations, or responsibilities shift quickly and unexpectedly. With longer periods of time, the team effort can drift, miss deadlines, or become sidetracked by other work. As projects progress and team members get busy with their tasks or other projects, memory about assignments, deadlines, and operations can fade. Projects often begin with regular meetings, but those meetings become irregular, disrupting the pace and flow of work, conversation, and ideas. Without frequent communication, team members can be unintentionally blindsided by new information, expectations, or changes in direction.

\section{Data Management and Analysis}

As projects grow in size and length, data and thinking are spread across time, space, and people, resulting in potential threats of losing track of data, good ideas, and assignments. As the volume of data builds, finding relevant information and managing the different items, such as transcripts, notes, and early ideas, becomes more difficult. Also, there are potential technical challenges of working across institutions in terms of computer hardware and software.

Analytically, details like definitions and uses of codes can drift or change altogether. Analysts may begin work with incomplete or outdated data, duplicate efforts, or lose keen insights and connections if they do not have clear guidelines for managing files and notes. Biases or differences in analytical styles can impede analytical progress when output does not match expectations. In our own experience, for example, some analysts prefer to work with paper copies, while others prefer electronic copies. We have to determine how to accommodate these 2 approaches to have a single, perpetual record of analysis that can be easily accessed for future iterations of the analysis. Finally, lack of early planning for writing up results can lead to delays and hard feelings about contributions and authorship.

\section{Strategies to Improve Teamwork}

Team Formation

Team leadership. Early in a project a team leaderoften the principal investigator (PI) — sets the tone for how the team can work together. These messages should be clear and can start with a discussion about the project's purpose and any unwritten hopes or expectations for the project. One technique is to craft a 1 - or 2-sentence sound bite that captures the essence of the project; repeat it often until the team adopts it as a common description of the project. The PI is responsible for making sure that the team has a common understanding of the project throughout the life of the project. To ensure a common focus, the PI should be involved from the beginning and be able to hear all voices, which he or she can meld into one. A team leader must also watch for signs that the team is not working well (silence, outbursts, missing deadlines, etc) and restore its function. Essentially, a team leader needs excellent management skills or assistance from others who can help manage people, time, and information.

Team timing. Convene the team as soon as possible. Even members who may not seem central to the project will benefit from early discussions. For instance, if the project entails a participatory style of research, it 
is important to include representatives of the communities, participants, agencies, or others at this early stage. Early discussions help build an overall clearer sense of project purpose, possible roles, and details of the project that will inform and guide work to come. Importantly, discussion starts orienting team members to the vocabulary of project-technical language, medical terms, context, names, and acronyms.

\section{Team Building}

Regular team meetings. Regular team meetings have been among our most effective methods for keeping members engaged and on track. Begin these meetings early in a project and schedule them in advance so they are on all the team members' calendars. When it seems there is little to justify a meeting, the team should still meet, if only to avoid getting out of the habit of meeting. Consider changing the format and focus of meetings to reenergize the team: focus a meeting on emerging ideas or engage in an open forum on ideas for publications. The team leader sets the tone of meetings, which should be comfortable. Establish norms for conducting open, respectful meetings. Have the team members agree to a few ground rules for listening, speaking, and handling disagreements.

Roles, responsibilities, and expectations. Early in a project ask each team member (do not assume) what specifically interests them about the project and any particular parts they feel strongly about. Ask again later in the project as members acquire more skill or better understand the goals and the remaining work, which may have changed.

\section{Data Management and Analysis Strategies} Analytical Biases and Work Styles

Spend a sufficient amount of time talking about these differences and troubleshoot how to accommodate them. The following are some major considerations to discuss: theoretical approaches to analysis (eg, phenomenology, hermeneutics, grounded theory), analytical style, (eg, lots of codes vs few codes, structured vs unstructured), and use of computers (eg, e-mail, electronic data vs paper). An analyst who is accustomed to unstructured coding, for example, may find a highly structured coding scheme difficult to work with, especially if coming into a project at an intermediate phase These discussions are helpful for understanding how to structure data collection and analysis and where talents and methods can be put to their best use.

\section{Data Management}

At the start of a project, think through how and where notes and files will be kept, who will be oversee them, and how they will be safeguarded. One of our most effective tactics is to appoint one person as a data manager. Almost all files, whether computer or paper, pass through him or her. The data manager cleans, compiles, and merges files for analyses and updates all team members on file status and accessibility. Early in a project, it is also worth a quick inventory of computers and software to determine members' preferences, training needs, software version compatibility, and data security

Common forms. Regularly use simple, familiar, and common forms at all phases of the analysis. Miles and Huberman $^{8}$ describe a number of ideas, but we have found a simple 3 -question summary form invaluable for all types of qualitative data collection: (1) What were the main issues or themes? (2) What are your impressions, concerns, ideas, or reflections? (3) What new or remaining questions do you have? Without consistent use of such forms, retrieving certain information can become a time-consuming search for data or ideas embedded in detailed notes or codes.

Coding conventions. If coding data is a major part of analysis, remind the team to routinely write down code definitions, annotate them, and revisit them. This recommendation sounds obvious, but it is especially important to update codes as the analysis progresses and discuss them periodically to identify inconsistencies, changes in meaning or use, and emerging sets of new codes. We found it helpful to agree on a few common coding conventions (using punctuation or specific naming conventions) to find codes or data of a certain type quickly. We often use a code called "Quotables," alone or in combination with other codes, to quickly retrieve segments of text that are particularly illustrative or potentially useful in a report.

Trim as you go. As the data grow and ideas emerge, the team needs to document these ideas and continue documenting as the process flows and decisions are made as to what to keep, discard, or reserve for later review. To keep members focused on the right tasks, revisit the original research question or project goals, and trim the ideas that might be important but are not within the scope of the project. Data grids have helped us identify major ideas and themes or major gaps in our analysis across data sources or team members (Figure 1). Sometimes we assign scores or symbols to themes to identify essential ones easily; or we use 0s and $1 \mathrm{~s}$ for quick calculations to count the presence or absence of themes across cases or within cases.

Intermediate goals or products. Intermediate products keep the team from putting off important tasks and help make midcourse corrections to data collection, analysis, and interpretation. One tactic is to ask team members to prepare 1 or 2 overhead slides with what they think are the 2 or 3 most important ideas emerging from the data, what evidence they have to support 
Figure 1. Sample theme grid.

\begin{tabular}{|c|c|c|c|c|c|}
\hline Data Source & Theme A & Theme $\mathbf{B}(!)$ & Theme C (!) & Theme D (?) & Theme-E \\
\hline Interview A & $\checkmark$ & $\checkmark$ & $\checkmark$ & $\checkmark$ & $\checkmark$ \\
\hline Interview B & $\checkmark$ & $?$ & $\checkmark$ & $?$ & $x$ \\
\hline Interview C & $x$ & $\checkmark$ & $\checkmark$ & $x$ & $x$ \\
\hline Interview D & $x$ & $\checkmark$ & $\checkmark$ & $x$ & $x$ \\
\hline Interview E & $\checkmark$ & $x$ & $\checkmark$ & $\checkmark$ & $x$ \\
\hline Interview F & $?$ & $?$ & $?$ & $?$ & $x$ \\
\hline Focus group 1 & $\checkmark$ & $x$ & $\checkmark$ & $\checkmark$ & $x$ \\
\hline Field notes 1 & $\checkmark$ & $x$ & $x$ & $\checkmark$ & $x$ \\
\hline $\begin{array}{l}\boldsymbol{V}=\text { theme preser } \\
\boldsymbol{X}=\text { theme absent } \\
?=\text { unsure; revien } \\
(!)=\text { essential ther } \\
(?)=\text { keep discuss } \\
\text { Theme = interesti }\end{array}$ & ant now. & & & & \\
\hline
\end{tabular}

those ideas, and specifically where to find them in the data. Additionally, inviting outside experts to join a meeting can help team members get serious about moving the analysis along or address stuck positions. Negotiate reasonable deadlines to give a specific goal- or product-oriented target to keep the analysis on track.

Regular documentation. At team meetings, keep notes about project administration, decisions, task assignments, and the analytical process. For example, document why specific codes were used instead of others, how merging specific codes came about and what they include, or who is responsible for the next data collection or analytical steps. Keep track of the smaller tasks that might get assigned and forgotten because they seem less important. During more-intensive analytical meetings, consider tape recording and transcribing conversations. Send a meeting summary to members and keep summaries in an easily accessible place.

Writing up results. Books have been written as guides to writing up qualitative research ${ }^{16-21}$; however, these guides do not address the process of collaborative writing. Writing collaboratively mentors inexperienced writers, alleviates blank-page anxiety, ${ }_{1}{ }^{17}$ and provides a good check on the accuracy of the reporting. It saves time in the long run to start brainstorming and outlining potential manuscripts and writing tasks early in the process of qualitative analyses. Establish author guidelines, roles, and expectations early in the process to avoid misunderstandings later. We have had the unfortunate experience of routing a manuscript to coauthors to find that we had inadvertently left a substantive contributor out of the loop. As ideas for manuscripts start, ask of the whole team which members would like to contribute to the written report and which members would like to lead; then route early drafts of an abstract to those team members, and ask whether there are others who should contribute. Simultaneously, be extremely clear about what contributions meet the guidelines for authorship.

\section{DISCUSSION}

Good qualitative research requires systematic methods by researchers who can account for the methodological and the analytical paths that led to the reported findings. In a team-based research setting, little should be left to chance. Processes and documentation become critical elements of teamwork. The goal is to foster team processes for efficient, rigorous, and thoughtful analysis; team members can then be confident in their analyses and products. The tools and strategies do not need to be rigid or highly structured, but they do need to be systematic and able to be audited. Qualitative researchers will benefit from further examination and discussion of effective, fieldtested, team-based strategies.

To read or post commentaries in response to this article, see it online at http://www.annfammed.org/cgi/content/full/3/4/360.

Key words: Qualitative research; evaluation studies; research methods; team work

Submitted May 4, 2004; submitted, revised, January 21, 2005; accepted January 30, 2005.

Portions of this manuscript were presented at the Primary Care Research Methods \& Statistics Conference, December 2003. San Antonio, Tex.

Acknowledgement: We would like to thank our many team members, analysts, and participants who have contributed greatly to our efforts and learning. 


\section{References}

1. Richards L. Qualitative teamwork: making it work. Qual Health Res. 1999;9:7-10

2. Sofaer S. Qualitative research methods. Int J Qual Health Care. 2002;14:329-336.

3. Marshall C, Rossman GB. Designing Qualitative Research. 2nd ed. Thousand Oaks, Calif: Sage Publications, Inc; 1995.

4. Treloar C, Graham ID. Multidisciplinary cross-national studies: a commentary on issues of collaboration, methodology, analysis, and publication. Qual Health Res. 2003;13:924-932.

5. Barry CA, Britten N, Barber N, Bradley C, Stevenson F. Using reflexivity to optimize teamwork in qualitative research. Qual Health Res. 1999;9:26-44.

6. Martinez-Salgado C. Unexpected findings of a female team in Xochimilco, Mexico. Qual Health Res. 1999;9:11-25.

7. Thomas MD, Blacksmith J, Reno J. Utilizing insider-outsider research teams in qualitative research. Qual Health Res. 2000;10:819-828.

8. Miles MB, Huberman AM. Qualitative Data Analysis: An Expanded Sourcebook. 2nd ed. Thousand Oaks, Calif: Sage Publications, Inc; 1994.

9. Sprokkereef A, Lakin E, Pole CJ, Burgess RG. The data, the team, and the ethnograph. In: Burgess RG, ed. Computing and Qualitative Research. Vol. 5. Greenwich: Jai Press, Inc, 1995:81-104.

10. MacQueen KM, McLellan E, Kay K, Milstein B. Codebook development for team-based qualitative analysis. Cult Anthropol Methods. 1999;10:31-36.
11. Crabtree BF, Miller WL, eds. Doing Qualitative Research. 2nd ed. Thousand Oaks, Calif: Sage Publications, Inc; 1999.

12. Rose K, Webb C. Analyzing data: maintaining rigor in a qualitative study. Qual Health Res. 1998;8:556-562.

13. Morse JM. Myth \#93: reliability and validity are not relevant to qualitative inquiry. Qual Health Res. 1999;9:717-718.

14. Yin RK. Enhancing the quality of case studies in health services research. Health Serv Res. 1999;34:1209-1224.

15. Malterud K. Qualitative research: standards, challenges, and guidelines. Lancet. 2001;358:483-488.

16. Morse J, Richards L. Read Me First for a User's Guide to Qualitative Methods. Thousand Oaks, Calif: Sage Publications; 2002.

17. Richardson L. Writing: a method of inquiry. In: Denzin N, Lincoln Y, eds. Collecting and Interpreting Qualitative Materials. Thousand Oaks, Calif: Sage Publications; 1998:345-367.

18. Strauss A, Corbin J. Basics of Qualitative Research: Grounded Theory Procedures and Techniques. Newbury Park, Calif: Sage Publications; 1990.

19. Topping K, Nixon J, Sutherland J, Yarrow F. Paired writing: a framework for effective collaboration. Reading. 2000;34:79-89.

20. Wolcott H. Writing Up Qualitative Research. 2nd ed. Thousand Oaks, Calif: Sage Publications; 2001.

21. Wolcott H. Writing Up Qualitative Research. Thousand Oaks, Calif: Sage Publications; 1990 